\title{
Knowledge and Attitudes on Fetal Anomalies among Pregnant Women in Teaching Hospital Mahamodara, Galle
}

\author{
K.T.G.Kanchana', P.Youhasan ${ }^{2}$ \\ ${ }^{1}$ Department of Nursing, Kaatsu International University, Sri Lanka \\ ${ }^{2}$ Department of Medical Education \& Research, Eastern University, Sri Lanka
}

Article Info
Article history:
Received Jul 10, 2018
Revised Nov 10, 2018
Accepted Nov 21, 2018

\section{Keyword:}

Attitudes

Birth defects

Knowledge

Pregnant women

Teaching hospital

\begin{abstract}
Fetal anomalies significantly contribute towards neonatal mortality worldwide. In Sri Lanka major cause for neonatal deaths is fetal anomalies $41 \%$. A Descriptive cross-sectional study was conducted in Antenatal clinic, Teaching Hospital, Mahamodara. An interviewer-administered, pretested questionnaire was used. Hundred and fifty pregnant women participated in this study. Majority; 105 (70\%) were found in the age of below 30 years, and $80(53.3 \%)$ educated up to G.C.E. Ordinary Level. $83(53.3 \%)$ were multigravida and 93(62\%) were planned pregnancies. Higher proportion of the participants; $92(61 \%), 88(56.7 \%)$ and $123(82 \%)$ had good knowledge on the risk factors, pre conception care and on preventive actions related to birth defects respectively. Significant proportion $(26.7 \%)$ had poor knowledge regarding birth defects. There are $143(95.3 \%)$ of the participants interested to know more information on birth defects, $72 \%$ believed birth defects were due to evil spirits. Even though $52 \%$ of women did not want to terminate their pregnancy if they had a fetus with anomalies, $80.7 \%$ of them opined that the termination of pregnancy with birth defected should be legalized. The educational level, parity and planning of current pregnancy of the participants were significantly correlated $(\mathrm{p}<0.05)$ with their knowledge on pre conception care, preventive actions, knowledge on risk factors on birth defects.
\end{abstract}

Copyright $\odot 2018$ Institute of Advanced Engineering and Science. All rights reserved.

\section{Corresponding Author:}

K.T.G.Kanchana,

Department of Nursing,

Kaatsu International University,

Koswatta, Sri Lanka.

Email: gayaniyp1629@gmail.com / gayani@kiu.lk

\section{INTRODUCTION}

Congenital anomaly is a permanent change produced by an intrinsic abnormality of development in a body structure during prenatal life [1], [2]. There may be structural fetal anomalies like, anencephaly, cleft pallet, hirschsprungs disease, infant polycystic kidney diseases, renal agenesis, spina bifida etc. or maybe genetic anomalies like Trisomy 21, Turners syndrome and genetic disorders like thalassemia etc. [1], [3], [4].

The causes of congenital anomalies are divided into four broad categories, genetics, environmental, multifactorial and unknown. A genetic cause is considered to be responsible in as many as $10-30 \%$ of all congenital anomalies, environmental factors in 5-10\%, multifactorial inheritance in 20-35\% and unknown causes were responsible for 30-45\% of cases [5]. In world 1 in 33 babies currently born with a birth defect, and with birth defects being a leading cause of morbidity and mortality in children according to WHO 2010 report. About 3 million fetuses and infants are born each year with major congenital anomaly worldwide. Globally, it is estimated that every year over three million children die due to congenital anomalies [6]. In addition, another three million babies born with a congenital anomaly and do not access care at birth may 
be disabled for life [7]. The risk of major congenital anomalies in industrialized countries is around $3-5 \%[8]$.

Factors influencing fetal anomalies include genetic factors, environmental factors like pollution, radiation, maternal factors like diabetic mellitus, and late age of pregnancy, uncertain medications, nutrition deficiencies, maternal infections, obesity and etc. A study has shown mothers of gravidity 4 or more had significant higher incidence of having congenitally malformed child (40\% of them CNS malformation) when comparing to mothers of lower gravidity [3]. However fetal anomalies can occur in any family regardless of age, gender, social level, race, health status, economic status or education. But those above mention exposures may or can increase development of congenital anomalies [3]. Most children who are born with major congenital anomalies and survive infancy are affected physically, mentally or socially and can be at increased risk of morbidity due to various health disorders. In Sri Lanka every year nearly $1.13 \%$ of infant deaths occur due to fetal anomalies. The rate of fetal anomalies in Sri Lanka is 6.77\% according to World Health Organization (WHO) 2015 World Health Ranking publication. In Sri Lanka main causes for neonatal deaths still congenital anomalies $41 \%$, prematurity $26 \%$, birth asphyxia $12 \%$ and neonatal infection $11 \%$ [6], [9].

In Sri Lanka unmet need for family planning of $8.4 \%$ and teenage pregnancy rate $6.5 \%$ had been reported [8], [10]. Teenage pregnancies were significantly associated with poor education, poverty, anemia, pregnancy induced hypertension and preterm delivery which ultimately will be a risk factor for giving birth to a congenitally abnormal baby [8], [11].

Though worldwide campaign has been carried out to raise awareness about fetal anomalies among the in general public and especially among women at childbearing age, Sri Lanka does not have a wellorganized program of pre conceptual care other than prenatal supplementation with folic acid and rubella vaccination [12]. However the national data for the population coverage of folic acid supplementation is not available in Sri Lanka. According to a research finding in Sri Lanka, knowledge of the value of early registration with a Public Health Midwife (PHM) and preconception rubella vaccination, and the risks associated with increased age, consanguinity, and exposure to passive smoking were satisfactory [8]. Knowledge regarding pregnancy planning, awareness of Pre Conception Care (PCC), and effects of prepregnancy weight on fertility, folic acid supplementation, birth defects, fertile period and birth spacing were unsatisfactory; which is need to be addressed. As well as the majority of the risk factors are preventable in birth defects and in Sri Lanka according UN World Abortion Policies 2011- UN Department of Economic and Social Affaires/Population Division details, section 306 of the Penal Code "Whoever, before the birth of any child, does any act with the intention of thereby preventing that child from being born alive, or causing it to die after its birth, and does by such act prevent that child from being born alive, or causes it to die after its birth, shall if such act be not caused in good faith for the purpose of saving the life of the mother, be punished with imprisonment of either description for a term which may extend to ten years, or with fine or with both"; due to this law though the fetus with birth defect is identified earlier parents don't have legal right to terminate pregnancy in Sri Lanka [13], [14].

Therefore, the study aimed to assess whether the knowledge of fetal anomalies in pregnant women have relationship with socio-demographic characteristics, to assess the knowledge of pregnant women regarding pre conceptual care, causes, risk factors and preventive knowledge regarding fetal congenital anomalies, to assess the attitudes of pregnant women towards fetal anomalies and to assess amount of votes given by pregnant mothers reflecting neediness to rectify legal laws for termination of fetus with anomalies/birth defects. Up to now few studies on knowledge and attitudes on fetal anomalies among pregnant women have been conducted in Sri Lanka. Proper knowledge about fetal anomalies can lead to early diagnosis, treatments and effective primary prevention of fetal anomalies which is an achievable goal [2], [15].

\section{RESEARCH METHOD}

A descriptive cross-sectional study was conducted in Antenatal clinic of Teaching Hospital, Mahamodara. We were assuming that $6.77 \%$ of fetal anomaly prevalence in Sri Lanka according to WHO 2014 World Health Ranking report, the required sample size of 150 had been calculated. An intervieweradministered, pretested questionnaire was used.

There are three sections included in the instrument: socio demographic details of the participants (Part A), knowledge regarding congenital/fetal anomalies (Part B) and attitudes of pregnant mothers regarding birth defects/fetal anomalies (Part C). Part (A) contains socio demographic details of the participant's; area or home town, age, civil status, religion, educational level, occupation, monthly income, parity and current pregnancy (planned or not planned). Part (B) is to assess maternal specific knowledge on

IJPHS Vol. 7, No. 4, December 2018: $231-235$ 
fetal anomalies, specific knowledge on risk factors and causes, specific knowledge on pre conception care and specific knowledge on preventive actions on birth defects/ fetal anomalies.

There were 21 questions to assess maternal knowledge on fetal anomalies. Specific knowledge on risk factors and causes were evaluated using 11 separate questions. Seven specific questions were used to assess the maternal knowledge on pre conception care knowledge and preventive actions on birth defects were assessed using 8 questions. All the questions are close ended questions. Each correct answer score one mark and zero mark given for each wrong answer. Part (C) is to assess attitudes of the pregnant mothers towards fetal anomalies/birth defects. 10 separate questions were used for assessing attitudes of pregnant mothers regarding birth defects. Part $\mathrm{B}$ and $\mathrm{C}$ were assessed based on the marks them obtained. It was categorized as: 100-60\% Good knowledge; 59.9-40\% Average knowledge; 39.9-00\% Poor knowledge

\subsection{Statistical analysis}

Data entry and analysis were conducted using SPSS 20 (Percentages and, Pearson Chi Squired test was used to determine the association between the knowledge and the attitudes on birth defect among the participants and their socio-demographic characteristics) and Excel 2007.

\subsection{Ethical aproval}

Approval for implementation of this study was obtained from ethical review committee of Faculty of Medicine, University of Ruhuna and permission to visit antenatal clinic was obtained from Director of Teaching Maternity Hospital Mahamodara, Galle.

\section{RESULTS AND ANALYSIS}

A total of 164 consented to participate in the study and among that 150 participants were selected for research as 10 were used to pretest (Pilot Study) and 4 participants were willingly withdrawn from the study after completing a part of questionnaire.

\subsection{Knowledge regarding birth defects}

Table 1 shows the majority of the pregnant mothers were from Galle (64\%), $70 \%$ of mothers' age were less than 30 years, married (92\%) and Buddhist (91.3\%). Multiparous or grand-parous women $(55.3 \%)$ and they were educated up to Ordinary Level (53.3\%). 88.7\% was unemployed and (42\%) of their monthly income lies between 15000-25000 Sri Lankan rupees, 62\% of women's current pregnancy was pre planned.

Table 1. Association of Demographic Factors on the Knowledge Regarding Birth Defects

\begin{tabular}{|c|c|c|c|}
\hline Knowledge type & Demographic factor & Pearson Chi - Value & $\mathrm{p}-$ value $(2$ sided $)$ \\
\hline \multirow{5}{*}{$\begin{array}{l}\text { Maternal specific knowledge on } \\
\text { birth defects. }\end{array}$} & Education & $26.273^{*}$ & $0.001 *$ \\
\hline & Religion & $17.212 *$ & $0.028 *$ \\
\hline & Planning of current pregnancy & $21.980 *$ & $0.000 *$ \\
\hline & Education & $19.508 *$ & $0.012 *$ \\
\hline & Parity & $6.303^{*}$ & $0.043^{*}$ \\
\hline \multirow{2}{*}{$\begin{array}{l}\text { Maternal specific knowledge on } \\
\text { risk factors related to birth } \\
\text { defects. }\end{array}$} & Planning of current pregnancy & $13.111^{*}$ & $0.001 *$ \\
\hline & Planning of current pregnancy & 22.556 & $0.001 *$ \\
\hline \multirow{2}{*}{$\begin{array}{l}\text { Maternal specific knowledge on } \\
\text { pre conception care. }\end{array}$} & Education & $23.164 *$ & $0.003^{*}$ \\
\hline & Civil status & $35.559 *$ & $0.001 *$ \\
\hline \multirow{2}{*}{$\begin{array}{l}\text { Maternal specific knowledge on } \\
\text { prevention actions on birth } \\
\text { defects }\end{array}$} & Education & $29.788 *$ & $0.001 *$ \\
\hline & Planning of current pregnancy & $23.245^{*}$ & $0.001 *$ \\
\hline
\end{tabular}

* -P value less than 0.05

Fifty four percentage of the women not aware about the foods rich in folic acid thought $84 \%$ of the pregnant women knew that folic acid intake should be start before getting pregnant and $90 \%$ of the women knew it is important to take folic acid during first 3 months in pregnancy. Specific knowledge on birth defects with good knowledge $69.3 \%$, specific knowledge on risk factors and causes related to birth defects with good knowledge $61 \%$, specific knowledge on pre conceptual care with good knowledge $58.7 \%$ and specific knowledge on preventive action with good knowledge $82 \%$. Significant proportion $(26.7 \%)$ had poor knowledge regarding birth defects. 
According to the Pearson Chi Test; there is an association between maternal specific knowledge on birth defects with religion, educational level, planning of current pregnancy, an association between maternal specific knowledge on risk factors related to birth defects with educational level, parity and planning of current pregnancy and an association between maternal specific knowledge on pre conception care with, educational level and planning of current pregnancy.

\subsection{Attitudes regarding birth defects}

Seventy-six percentage of pregnant mothers received information regarding birth defects from PHM. 87.3\% Of pregnant mothers had positive and satisfactory attitudes towards birth defects as shown in Table 2. Majority of the participant wish to know more details on birth defects $(95.3 \%), 72 \%$ believed that the birth defects are caused by evil spirits and they feel pity (90\%) and wanting to help such children $(81.3 \%)$.

Seventy-seven point three percentages agreed with seeking help from spiritual actions for the defected children by birth. Sixty-three point three percentages did not think defected child is a burden for their parents and they do not wish abandons the child $(65.3 \%)$. Majority wishes to terminate the pregnancy if they conceive a fetus with birth defect $(82.7 \%)$ and $80.7 \%$ of them opined that the termination of pregnancy with birth defected should be legalized in Sri Lanka. There was a significant association between maternal level of knowledge and attitudes on birth defects as the $\mathrm{p}=0.001$, an association between the attitudes on birth defects and there level of education $p=0.043$ an the association between the attitude and knowledge on risk factors $\mathrm{p}=0.001$ and an association between knowledge on preventive actions and the attitude of on birth defects $\mathrm{p}=0.001$. In the study sample $87.3 \%$ of pregnant mothers had positive and satisfactory attitudes which represent the majority.

Table 2. Frequency of Attitudes

\begin{tabular}{ccc}
\hline Attitude & Frequency & Percentage \\
\hline Positive - satisfactory attitudes & 131 & 87.3 \\
Negative- unsatisfactory attitudes & 19 & 12.7 \\
\hline
\end{tabular}

\section{CONCLUSION}

Pregnant women in Galle had good knowledge on Birth Defects. The knowledge on birth positively correlates with the level of education, parity and planning of current pregnancy of the participants. Significant proportion of women's had poor knowledge regarding birth defects according to the WHO 2016 Report.

The attitudes regarding birth defects seem to be positively correlated with their level of education and level of knowledge. There is a need for legalizing laws for termination of a birth defected pregnancy. Previous studies and experiences had showed that the care and prevention of birth defects are feasible and can be cost-effective.

To improve knowledge and attitudes regarding birth defects as well as the preventive knowledge; medical officers of health, public health midwives and nurses as well as general practitioners should be motivated and trained to provide preconception health education, preventive actions on birth defects and knowledge on risk factor and causes for birth defects to women in their booking visit, newly wedded couples and women in reproductive age, educate the community, health professionals and workers, policy makers, the media, and other stakeholders about birth defects and the opportunities for effective care and prevention, promote family planning, allowing couples to space pregnancies, plan family size, define the ages at which they wish to complete their family and reduce the proportion of unintended pregnancies which will ultimately help to reduce the number of unplanned pregnancies and reducing the rate of not having pre conception care before getting pregnant, development of appropriate information, education and communication and outreach materials should inform women of true causes for birth defects which help to reduce the burden of guilt they feel, the stigmatization from the community, and provide guidance on caring for women who have pregnancy outcomes and have children with disabilities due to birth defects, educate to the couple can take with their health care provider to maximize the chances of a planned pregnancy and a healthy pregnancy, providing information to general public on referral services for treatment, surgery, care and rehabilitation; community rehabilitation services; and family support programmes and institutions and organizations which provide care and education for handicapped children with birth defects, strengthening researches and studies on etiology, risk factors, diagnosis and prevention of congenital anomalies among fetus should be encouraged, salt iodization/fortification of the food supply with folic acid and irons supplementation or food fortification and 
improve health infrastructure facility are few of recommendation can be done in order to improve knowledge and attitudes of pregnant mothers regarding birth defects.

The data from the current study probably reflects to a significant degree of the situation in the general population in the Galle district because approximately $85 \%$ of child deliveries in Sri Lanka occur in tertiary care facilities providing hospitals. Teaching Hospital, Mahamodara is one of the largest tertiary cares providing hospital in the southern province. The demographic characteristics of the study population will be probably reflecting the general population in the Galle district.

\section{ACKNOWLEDGEMENTS}

I thank all pregnant women for their collaboration in the study. Special thanks for Faculty of Medicine, University of Ruhuna, Chief supervisor Dr.M.F.M.Rameez and Mr.P.Youhasan for their continuous support during the study.

\section{REFERENCES}

[1] Stevenson A; Oxford Dictionar of English. $1^{\text {st }}$ ed.New York, NY: Oxford University Press,13:9780199571123. 2010.

[2] Christianson, A., Howson, C. andModell, B; "March of Dimes-Global report on birth defects-The hidden toll of dying and disabled children”. New York: March of Dimes Birth Defect Foundation. 2006

[3] Peter, IA., Ekong, MB., Theresa, BE., Umoh, IU., Edgha, IA., Davies, KG. and Mbudugha, CC; "Attitude and knowledge of pregnant women attending antenatal clinics at St. Luke's Hospital, Anua in Uyo, Nigeria towards congenital anomalies". Ibom Medical Journal,6(2):34-40. 2013

[4] Vidhya, R. and Raju, S; "Adjustment and attitude of parents of children with mental retardation." J Indian Acadamy Applied Psychology.33(1). p137-141; 2014

[5] Masoumeh, P., Vahid, K., Hamid, A., Khoshen, K. and Samira, K; " Knowledge of pregnant women about congenital anomalies: A cross sectional study in North of Iran”. Indian Journal of Health Sciences.,8(1), p41-47. 2015

[6] WHO; "World Health Ranking - Live Longer Live Bette" $r$; 2014. Accessed at: http://www..worldlifeexpectancy.com/sri lanka - congenital anomalies [Accessed 30 Mar. 2016].

[7] United Nations; “ The Millennium Development Goals Report 2015”. 1st ed. New York: United Nations. ISBN 978-92-1-1013207; 201

[8] Patabendige, M., Goonewardena, IMR; "Preconception care recieved by women attending antenatal clinics at A Teaching Hospital In Southern Sri Lanka”. Galle : Sri Lanka Journal Of Obstetrics And Gynaecology, 2013

[9] United Nations; "Abortion Policies and Reproductive Health around the World 2014" ; United Nations Department of Economic and Social Affairs Population Division. 2014.

[10] Fernando, N., Perera, B.,Goonawardena, M. and Ostbye, T; "Factors associated with sexual behavior among Sri Lankan adolescents". Galle Medical Journal. 14(1). p39-44.

[11] Gitsle, JT., Verhoeven, PS., Mannien, J., Martin, L., Reider, HS. and Eveilien, S; "Factors affecting the uptake for screening test for congenital anomalies; A multicentre prospective cohort study" .BMC Pregnancy and Childbirth 14(1). p264-276; 2014.

[12] Birth Defects: Sixty-Third World Health Assembly. (2010). Available at: http://apps.who.int/gb/ebwha/pdf_files/WHA63/A63_10-en.pdf. [Last cited on 2016 March 12].

[13] Abeyesekera, S; Abortion in Sri Lanka in the Context of Women's Human Rights; Reproductive Health Matter.9. p87-94; 1999.

[14] Annual Report on Family Health 2013 Family Health Bureau Ministry of Health. Available at: http://ministry of health sri lanka [ Accessed 30 Mar.2016]

[15] Dias,T; “Importance of first trimester scan screening for early fetal structural anomalies". Sri Lanka Journal Of Obstetrics and Gynaecology.2011;33(1):183-188. 2011. 